\title{
Foreign Body-Induced Liver Abscess: Is Surgery Indispensable?
}

\section{Amroun $\mathrm{KL}^{1 *}$, de Mestier $\mathrm{L}^{2}$, Djerada $\mathrm{Z}^{3}$, Malgoire $\mathrm{JY}^{1}$, Belkebir $\mathrm{M}^{4}$ and Kianmanesh $\mathbf{R}^{1}$}

${ }^{1}$ Service de Chirurgie Générale, Digestive et Endocrinienne, CHU Robert-Debré, boulevard du Général Koenig 51092 Reims Cedex, France 2Service d'Hépato-Gastroentérologie et Oncologie Digestive, CHU Robert Debré, boulevard du Général Koenig 51092 Reims Cedex, France ${ }^{3}$ Service de Pharmacologie - Toxicologie, CHU Robert Debré, boulevard du Général Koenig 51092 Reims Cedex, France

${ }^{4}$ Service de Radiologie, CHU Robert Debré, boulevard du Général Koenig 51092 Reims Cedex, France

\begin{abstract}
A case of hepatic abscess that developed secondary to a foreign body migration is reported herein. In most published cases, the diagnosis is done after failure of medical treatment or recurrence of the abscess. CT-scan findings may lead to an early diagnosis, like in this case. The patient was treated by percutaneous abscess drainage and adapted antibiotherapy. Because of remarkable co-morbid conditions, no removal surgery was performed. No recurrence of the abscess could be observed after eighteen months of follow up. Foreign body is a rare cause of liver abscess that may not be ignored by clinicians. Although removal surgery is the mainstay of its treatment, a medical approach could be attempted with efficacy.
\end{abstract}

Keywords: Liver; Abscess; Foreign body; Antibiotherapy; Drainage

\section{Introduction}

Perforation of the gastrointestinal tract caused by ingested foreign bodies is uncommon and secondary formation of hepatic abscess is even rarer but recognized as a cause of liver abscess treatment failure [1]. Most cases of liver abscesses caused by the migration of a foreign body are initially misdiagnosed as cryptogenic liver abscesses. Toothpicks, chicken and fish bones are the most common causes of foreign body ingestion. Metallic foreign bodies are less frequent [2]. We report here a case of ingested foreign body that migrated to the left lobe of the liver.

\section{Case Report}

A 62 year-old woman presented at Emergency Care Unit with abdominal pain located in the epigastrium and right hypochondrium, fever, chills and asthenia. There was no particular history of recent travelling or foreign body ingestion. She had significant medical history of obesity (body mass index at 33), arterial hypertension, insulindependent diabetes mellitus complicated with macro-angiopathy, myocardial infarction 5 years before and hypertrophic cardiopathy, severe sleep apnea syndrome, a biliary cyst located in the right liver and finally hypothyroidism. Her medication was: verapamil, atorvastatin, irbesartan, levothyroxine, metformin and basal-

Bolus insulin therapy (insulin lispro and insulin glargine). At physical examination blood pressure was $160 / 75 \mathrm{mmHg}$, heart rate was $85 / \mathrm{min}$, respiratory rate was $20 / \mathrm{min}$, and body temperature was $38.9^{\circ} \mathrm{C}$. There was no disturbance of transit and no jaundice. There was a painful palpation of the epigastrium and the right hypochondrium, with no sign of peritoneal irritation or abdominal mass. The rest of the abdomen was soft.

The laboratory data were as following: white blood count: 15100/ $\mathrm{mm}^{3}$, neutrophil count: $12125 / \mathrm{mm}^{3}$, C-reactive protein $315 \mathrm{mg} / \mathrm{L}$, fibrinogen $11.1 \mathrm{~g} / \mathrm{L}$, gamma-glutamil transferase $100 \mathrm{UI} / \mathrm{L}(\mathrm{N}<35)$, alkaline phosphatase $133 \mathrm{UI} / \mathrm{L}(\mathrm{N}<120)$. Levels of transaminases and total bilirubin were normal. Hemocultures were sterile, retrospectively.

Plain chest and abdomen X-rays radiographs were normal. A CT-scan was performed and found a large intra hepatic collection in the segment 3 of the liver with a peripheral contrast enhancement, measuring: $8 \times 5 \times 8 \mathrm{~cm}$ (Figures 1a and $1 \mathrm{~b}$ ). A spontaneous hyperdense linear image measuring 4 could be observed, that seemed to come from the antro-pyloric region to the abscess.
An intravenous antibiotherapy was initiated, composed of ceftriaxone $2 \mathrm{~g}$ once a day and metronidazole $500 \mathrm{mg}$ three times a day. The drainage of the abscess was performed under ultrasonographic guidance, draining purulent liquid. A Staphylococcus aureus was isolated on the examination of the drained fluid. An upper gastrointestinal endoscopy was performed and did not find any abnormal aspect of the gastric or duodenal mucosa, or perforation.

Antibiotherapy was secondary adapted with ofloxacine $200 \mathrm{mg}$ twice a day and clindamycine $600 \mathrm{mg}$ three times a day for a total duration of three weeks. This treatment led to a clinical improvement, indeed apyrexia and sedation of pain could be observed after three days of antibiotics taking. The drainage tube was removed at the fifth day after the ultrasonographic verification of the disappearance of the abscess.

A surgical extraction of the foreign body was discussed, but abstention was decided because of her significant morbidity conditions.

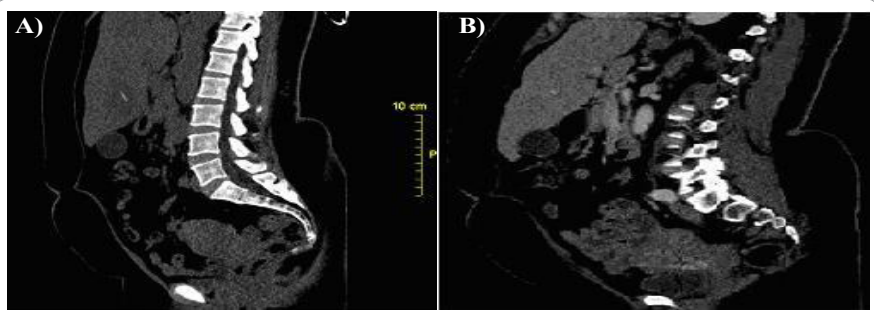

Figure 1: Sagittal section of abdominal CT-scan before (Figure 1a) and after (Figure 1b) contrast product injection. A) spontaneous hyperdensity located in the segment 3 of the liver. B) foreign body surrounded by a hypodensity with peripheral enhancement, suggesting an intrahepatic abscess.

*Corresponding author: KL Amroun, Service de Chirurgie Générale, Digestive et Endocrinienne, CHU Robert-Debré, boulevard du Général Koenig 51092 Reims Cedex, France, Tel: (+33)326787095; E-mail: lamroun@chu-reims.fr

Received August 31, 2012; Accepted September 26, 2012; Published Septembe 28, 2012

Citation: Amroun KL, de Mestier, Djerada Z, Malgoire JY, Belkebir M, et al. (2012) Foreign Body-Induced Liver Abscess: Is Surgery Indispensable? J Clin Case Rep 2:205. doi:10.4172/2165-7920.1000205

Copyright: (c) 2012 Amroun KL, et al. This is an open-access article distributed under the terms of the Creative Commons Attribution License, which permits unrestricted use, distribution, and reproduction in any medium, provided the original author and source are credited. 


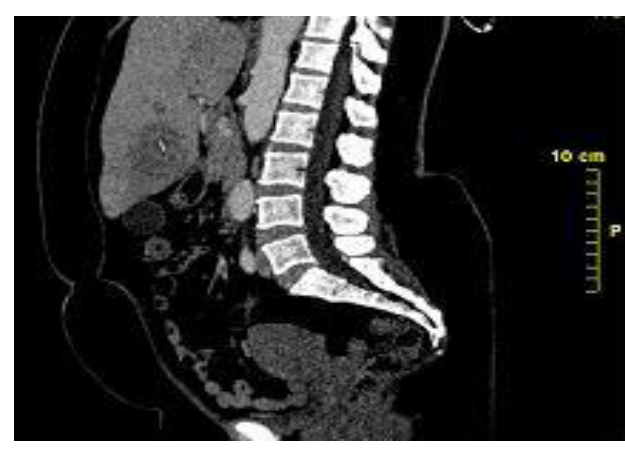

Figure 2: Sagittal section of abdominal CT-scan without enhancement, performed 15 months after diagnosis of foreign body-induced liver abscess. No modification of the foreign body, no reappearance of the intrahepatic abscess.

The patient underwent a close follow-up. Eighteen months later there was no clinical complaint. CT-scan and ultrasound examination did not find any recurrence of the abscess and confirmed the persistence of the foreign body in the left liver without further migration (Figure 2).

\section{Discussion}

The majority ( 80 to $90 \%$ ) of ingested foreign bodies migrate through the gastrointestinal tract and get evacuated in feces without any remarkable event within 1 week $[1,3]$. The development of a liver abscess secondary to the passage of a foreign body through the wall of the digestive tract is rare. That passage occurs across the stomach or duodenum wall and penetrates the left liver, or across the right colonic flexure wall for the right liver [2]. In our observation, seen that the foreign body was located in the segment 3 of the liver, its passage appears through the third duodenum. According to literature, most patients are male and the age at diagnosis ranges from 14 to 86 years [2]. Underlying diseases such as diabetes mellitus, cancer, liver cirrhosis and immunosuppression are predisposing factors of the formation of liver abscess [4-6]. Patients rarely report any history of foreign body ingestion $[1,3,7]$. The migration of the foreign body through the digestive wall may remains asymptomatic until the appearance of an abscess [8]. Symptoms due to perforation or impaction may be epigastric pain and upper gastrointestinal bleeding [9], associated to general symptoms such as fever, chills, anorexia, weight loss, and fatigue. Duration of symptoms may range from 1 day to 1 year [2]. Increased inflammatory markers such as leukocytosis and C-reactive protein can be observed. CT-scan is better than ultrasonography to identify the liver abscess and to highlight the foreign body, but its accuracy remains low [10]. Bacteriological findings may reveal digestive germs in most cases. The usual treatment consists in antibiotherapy, abscess drainage and foreign body removal. Surgical foreign body removal may be the treatment of choice if detected preoperatively, or in case of suspicion of bowel perforation [11]. Few authors report cases of treatment using antibiotics alone, eventually associated with percutaneous drainage, without removal of the foreign body [12]. In the present case, a treatment combining secondly-adapted antibiotherapy and percutaneous drainage was successful with a follow up of eighteen months. Thus, a medical approach with or without percutaneous drainage is an option to consider treating a liver abscess caused by a foreign body, especially if its surgical removal is contraindicated.

\section{References}

1. Kanazawa S, Ishigaki K, Miyake T, Ishida A, Tabuchi A, et al. (2003) A granulomatous liver abscess which developed after a toothpick penetrated the gastrointestinal tract: report of a case. Surg Today 33: 312-314.
2. Leggieri N, Marques-Vidal P, Cerwenka H, Denys A, Dorta G, et al. (2010) Migrated foreign body liver abscess: illustrative case report, systematic review, and proposed diagnostic algorithm. Medicine (Baltimore) 89: 85-95.

3. Horii K, Yamazaki O, Matsuyama M, Higaki I, Kawai S, et al. (1999) Successfu treatment of a hepatic abscess that formed secondary to fish bone penetration by percutaneous transhepatic removal of the foreign body: report of a case. Surg Today 29: 922-926.

4. Cheung YC, Ng SH, Tan CF, Ng KK, Wan YL (2000) Hepatic inflammatory mass secondary to toothpick perforation of the stomach: triphasic CT appearances. Clin Imaging 24: 93-95

5. Huang CJ, Pitt HA, Lipsett PA, Osterman FA Jr, Lillemoe KD, et al. (1996) Pyogenic hepatic abscess. Changing trends over 42 years. Ann Surg 223: 600607.

6. Mohsen AH, Green ST, Read RC, McKendrick MW (2002) Liver abscess in adults: ten years experience in a UK centre. QJM 95: 797-802.

7. Broome CJ, Peck RJ (2000) Hepatic abscess complicating foreign body perforation of the gastric antrum: an ultrasound diagnosis. Clin Radiol 55: 242 243.

8. Chintamani, Singhal V, Lubhana P, Durkhere R, Bhandari S,et al. (2003) Liver abscess secondary to a broken needle migration--a case report. BMC Surg 3: 8

9. Barros JL, Caballero A Jr, Rueda JC, Monturiol JM (1991) Foreign body ingestion: management of 167 cases. World J Surg 15: 783-788.

10. Goh BK, Chow PK, Quah HM, Ong HS, Eu KW, et al. (2006) Perforation of the gastrointestinal tract secondary to ingestion of foreign bodies. World $\mathrm{J}$ Surg 30: 372-377.

11. Chiang TH, Liu KL, Lee YC, Chiu HM, Lin JT, et al. (2006) Sonographic diagnosis of a toothpick traversing the duodenum and penetrating into the liver. J Clin Ultrasound 34: 237-240.

12. Yang CY, Kao JH, Liu KL, Chen SJ (2005) Medical treatment of fish bonerelated liver abscess. Clin Infect Dis 41: 1689-1690. 